\title{
Exposição Olhares, Dizeres e Saberes Sobre as Florestas Brasileiras
}

\author{
Exhibition: Looks, Sayings and Knowledge about the \\ Brazilians Forests
}

\section{RESUMO}

A Assembleia Geral da Organização das Nações Unidas (ONU) declarou 2011 o Ano Internacional das Florestas (Resolução 61/193), com o objetivo de concentrar esforços para sensibilizar todos os segmentos da sociedade sobre a necessidade de fortalecer o manejo sustentável e a conservação de todos os tipos de florestas para o benefício das gerações atuais e futuras. A ESALQ-USP, através do Departamento de Ciências Florestais e do Museu "Luiz de Queiroz", selecionou e organizou recursos artísticos e científicos em um projeto expositivo no qual arte e ciência dialogam e se complementam para atrair a atenção do visitante e sensibilizá-lo sobre a importância das florestas e a necessidade da sua conservação. Este artigo apresenta o projeto expositivo e relata os resultados dessa atividade.

Palavras-chave: Ano Internacional das Florestas. Extensão Universitária.

Biomas Florestais.

\section{ABSTRACT}

The General Assembly of the United Nations (UN) declared 2011 the International Year of Forests (A/Res/61/193), in order to concentrate efforts to raise awareness of all segments of society about the need to strengthen the sustainable management and conservation of all types of forests for the benefit of present and future generations. The ESALQ-USP, through the Department of Forest Sciences and the Museum "Luiz de Queiroz" resources selected and organized art and science exhibition on a project in which art and science dialogue and complement each other to attract the visitor's attention and make them aware about the importance forests and the need for conservation. This paper presents the exhibition design and reports the results of this activity.

Keywords: International Year of Forests. University extension. Forest biomes. 


\section{INTRODUÇÃO}

Com o objetivo de concentrar esforços para sensibilizar os governos, o setor privado, o terceiro setor e a população mundial sobre a necessidade de fortalecer a gestão sustentável, a conservação e o desenvolvimento sustentável de todos os tipos de florestas para o benefício das gerações atuais e futuras, a Assembleia Geral da Organização das Nações Unidas ( ONU) declarou 2011 o Ano Internacional das Florestas (Resolução 61/193).

A Secretaria do Fórum das Nações Unidas sobre as Florestas coordenou as atividades do ano e mobilizou, em colaboração com os Governos de cada país participante, universidades, centros de pesquisa, organizações governamentais e não governamentais de proteção às florestas, assim como empresas e grupos relevantes que atuam nessa área para que estabelecessem voluntariamente alianças para facilitar e promover atividades relacionadas ao Ano.

De acordo com a FAO (Organização das Nações Unidas para Agricultura e Alimentação), apesar de o desmatamento mundial ter diminuiu nos últimos dez anos, o problema ainda é grave. O relatório da Avaliação dos Recursos Florestais Mundiais 2011 indica que a área florestal mundial total é de cerca de 4 bilhões de hectares, o que representa $31 \%$ da superfície terrestre. Aponta, também, que Brasil e Indonésia, países que mais desmataram na década de 1990, reduziram significativamente suas taxas de desmatamento na última década. Entretanto, ainda persiste um grave problema: a forte pressão sobre as áreas de florestas primárias, que representam $36 \%$ do total da área florestal do mundo, mas foram reduzidas em 40 milhões de hectares no período [3]. Isso reforça a necessidade das ações propostas pela ONU.

A forma como nos apropriamos das florestas e dos recursos e serviços florestais está diretamente associada à visão que delas temos e à sua valoração econômica, ambiental, social e cultural.

Ao longo da história, as florestas já foram consideradas fontes de riqueza e exploradas à exaustão, o que resultou na extinção de espécie e em alterações edafoclimáticas. Foram também tratadas como fator crítico ao desenvolvimento econômico e risco à saúde pública, sendo derrubadas para dar lugar à agricultura, pecuária e urbanização.

Atualmente, as florestas são tema de diversas discussões no âmbito do desenvolvimento sustentável e da erradicação da pobreza. Isso, pela extrema importância para a vida no planeta, por estarem entre os maiores depósitos de carbono do mundo e abrigarem $80 \%$ da diversidade biológica mundial. Além disso, 300 milhões de habitantes moram em áreas florestais e as florestas são responsáveis por garantir diretamente a subsistência de 1,6 bilhões de pessoas [3]. Elas podem ser consideradas, ainda, razão de exacerbado sentimento nacionalista e de soberania nacional; ícone das maiores tragédias ambientais do planeta (queimadas, desflorestamento, extinção de espécies etc.); e contempladas como reservatórios de riquezas desconhecidas.

O Departamento de Ciências Florestais da Escola Superior de Agricultura "Luiz de Queiroz” da Universidade de São Paulo (LCF/ESALQ-USP) foi criado em 1961 e é referência nacional e internacional em silvicultura, manejo de florestas nativas e tecnologia de produtos florestais. Décadas de pesquisa e ensino sobre florestas geraram um rico acervo sobre o assunto, excelente ao propósito de sensibilizar a sociedade sobre 
as questões propostas pelo Ano Internacional das Florestas.

Em parceria com o Museu e Centro de Ciências, Educação e Artes "Luiz de Queiroz" e com o apoio do Fundo de Fomento às Iniciativas de Cultura e Extensão da Universidade de São Paulo, da Fundação Amazonas Sustentável e da Reserva da Biosfera da Mata Atlântica, foi organizada a Exposição Olhares, Dizeres e Saberes sobre as Florestas Brasileiras.

Nessa exposição foram utilizados recursos artísticos e científicos, organizados em um projeto expositivo no qual arte e ciência dialogam e se complementam para atrair a atenção do visitante e sensibilizá-lo sobre a importância das florestas e a necessidade da sua conservação.

O material expositivo foi construído de forma a viabilizar sua itinerância e, posteriormente, ser aproveitado como embrião para um museu sobre ciências florestais, que será instalado no Departamento de Ciências Florestais da ESALQ-USP.

\section{OBJETIVOS}

A exposição teve por objetivo geral sensibilizar crianças e adultos sobre a importância e a necessidade da conservação dos biomas florestais brasileiros, além de apresentar a contribuição do Departamento de Ciências Florestais da ESALQ-USP nessa área e sua atuação em diferentes regiões do país.

Visou, ainda:

" Contribuir com as iniciativas da ONU para o Ano Internacional das Florestas;

" Contribuir para a formação para a cidadania;

" Democratizar o acesso aos conhecimentos e bens culturais da universidade na área florestal;

" Complementar a formação acadêmica dos alunos bolsistas no desenvolvimento de projetos culturais;

" Ampliar a visibilidade do LCF/ESALQ-USP e do Museu “Luiz de Queiroz", especialmente na comunidade local e regional.

\section{O PROJETO EXPOSITIVO}

A exposição foi estruturada utilizando diferentes recursos que permitiram ao visitante o contato com diversas manifestações culturais sobre as florestas, tais como: painéis fotográficos, textos literários, objetos, visitas guiadas, ações educativas dirigidas, vídeos, material sonoro, pesquisas científicas, entre outros. Esse material foi organizado nos espaços internos e externos do Museu e Centro de Ciências, Educação e Artes “Luiz de Queiroz”.

Com a exposição se buscou, de um lado, ampliar os conceitos e a percepção sobre as florestas destacando a multiplicidade de formas de ocorrência e a riqueza biológica em cada uma delas: os biomas florestais brasileiros, a floresta plantada, a floresta urbana, os fragmentos florestais hoje cercados por áreas agrícolas, entre outros. 
De outro, sensibilizar o visitante através da beleza cênica e da riqueza cultural inserida nas florestas brasileiras.

O primeiro espaço, denominado "Fantasmas das Florestas", foi organizado na área externa em frente ao museu. Nele foram organizadas esculturas, construídas a partir de resíduos madeireiros como raízes, galhos e árvores mortas, ladeadas por painéis apresentando desenhos e textos literários sobre as lendas brasileiras relacionadas aos protetores das florestas: Anhangá, Boitatá, Curupira e Saci (Figura 1).

As esculturas foram construídas pelo graduando em Engenharia Florestal pela ESALQ-USP, Thiago Valiante, através do programa de estágio sobre aproveitamento de resíduos florestais desenvolvido no Laboratório de Movelaria e Resíduos Florestais do LCF/ESALQ-USP. A proposta foi baseada na exposição Ghost Forest, da artista inglesa Angela Palmer, montada na Praça do Parlamento em Copenhague por ocasião da Conferência do Clima em 2009.

O objetivo neste espaço foi causar um choque inicial pela sensação de destruição e ao mesmo tempo trazer os elementos da cultura popular relacionados à proteção das florestas, com textos e imagens que pudessem sensibilizar crianças e adultos.

Por se tratar de um espaço externo, essa parte da exposição ficou acessível ao público durante todo o tempo, gerando grande interesse e curiosidade nos visitantes do parque da ESALQ.

As grandes proporções, a beleza estética e os textos nos painéis complementares criaram uma boa oportunidade para reflexões sobre o futuro das florestas.

O segundo espaço foi projetado visando ressaltar a grandiosidade das florestas brasileiras. Montado na fachada do museu, foi composto por dois grandes painéis (de seis metros de altura cada) com a imagem de uma área da Mata Atlântica, pelos quais os visitantes passavam ao entrar no espaço interno da exposição (Figura 1).

No terceiro espaço, "O Descobrimento", o texto de Pero Vaz de Caminha e a imagem da Serra do Mar a partir do litoral paulista buscaram reproduzir o sentimento do descobridor estrangeiro ao se deparar com a Floresta Atlântica: "A estender olhos, não podíamos ver senão terra e arvoredo, que é tanto e tamanho, tão basto e de tanta qualidade que não se pode calcular..." [Pero Vaz De Caminha (c.1450-1500), carta ao rei de Portugal, dom Manuel, relatando o descobrimento do Brasil].

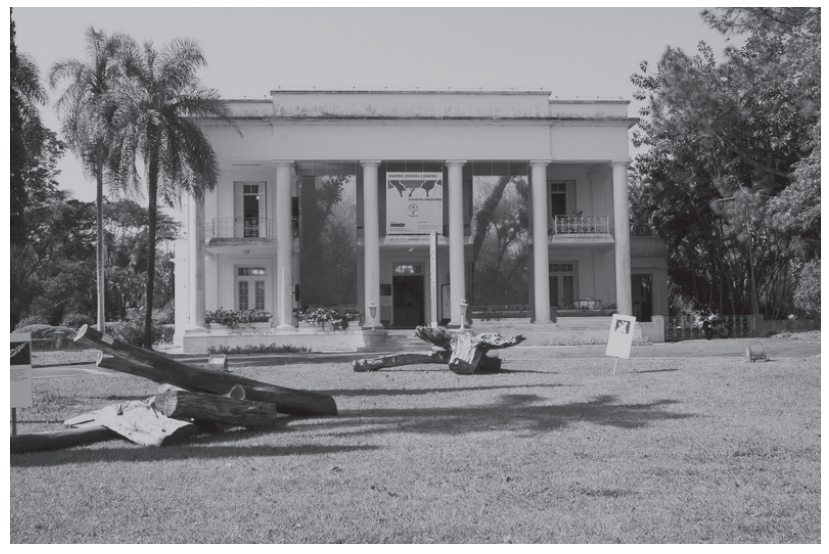

Figura 1 - Espaço "Fantasmas das Florestas" 
De maneira complementar, foram colocados à disposição do visitante, nesse mesmo espaço, textos de José de Anchieta, relatando as riquezas florestais brasileiras [1]; textos de botânicos estrangeiros, que até o período colonial realizaram inúmeras expedições para estudar e descrever a flora e fauna nativa; e discos de madeira utilizados em estudos de dendrocronologia, com indicações da idade da árvore, método para sua determinação e fatos históricos ocorridos durante sua vida, apontados nos anéis de crescimento.

No espaço seguinte foram disponibilizados ao visitante uma pequena xiloteca com painéis informativos sobre as espécies madeireiras, espécimes animais taxidermizadas, materiais interativos, jogos sobre aves e mamíferos e espécimes vegetais vivos com a intenção de mostrar a riqueza da biodiversidade nas florestas brasileiras (Figura 2). Sons de aves da região Amazônica ajudaram a criar a sensação de um passeio pela floresta.

O tema "Povos das Florestas" foi tratado na exposição através de imagens e textos que buscaram mostrar ao visitante que as florestas não são desertos verdes, mas sim espaços ocupados por uma grande diversidade de gente que hoje vive em estreita relação com as florestas brasileiras: indígenas, quilombolas, caiçaras, babaçueiros, ribeirinhos, caboclos, pescadores artesanais, extrativistas, seringueiros, camponeses, quebradeiras de coco, dentre outros. Buscou-se mostrar, também, que nessa convivência com o meio essas pessoas estabelecem suas atividades econômicas e de subsistência, constroem e reconstroem elementos da sua cultura (artesanato, religião, música, arte etc.) e, principalmente, possuem atualmente um papel fundamental na conservação dos recursos florestais [2,4] (Figura 3).

Para uma melhor compreensão de tais ideias, além de grandes painéis com belas imagens, textos literários e exposição de peças de artesanato produzidas com recursos florestais com madeira e fibras, no espaço "Cine Floresta” foram disponibilizados vídeos produzidos pelo Departamento de Ciências Florestais, pelo IMAZON (Instituto do Homem da Amazônia) e pela FAS (Fundação Amazônia Sustentável) mostrando atividades culturais, ações para o manejo florestal sustentável e a organização social desses povos em favor da conservação das florestas.

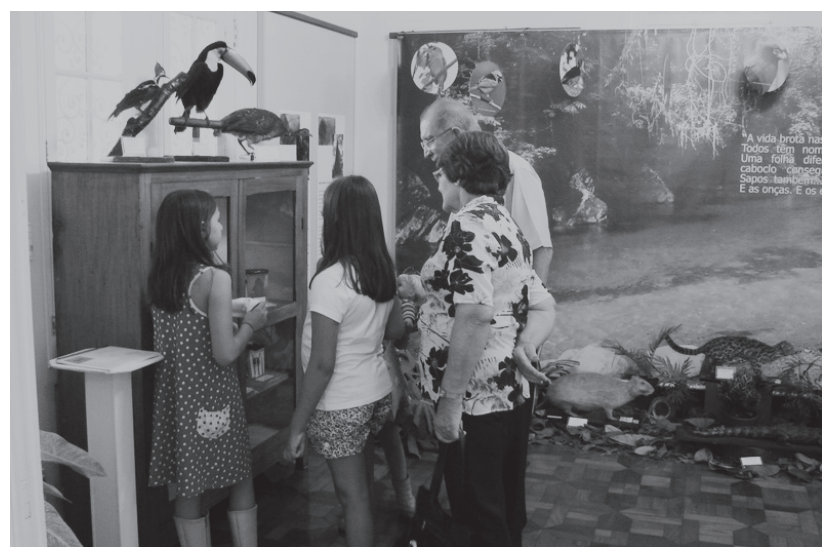

Figura 2 - Visitantes no espaço "Biodiversidade - Bem precioso" 


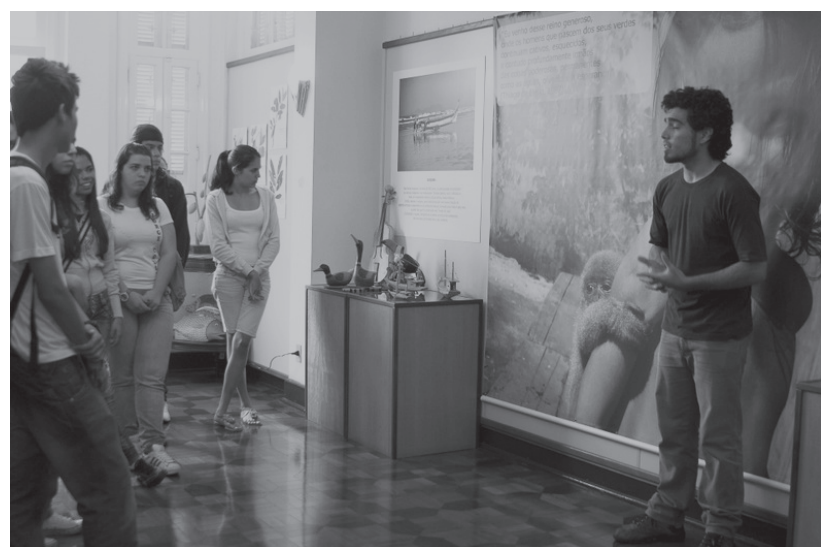

Figura 3 - Grupo de estudantes acompanhados por monitor no espaço "Povos da Floresta"

No espaço “Florestas e Sobrevivência Humana - Produtos e Serviços Florestais”, o visitante era convidado a refletir sobre a importância das florestas no seu cotidiano. Móveis, diferentes tipos de papéis, carvão, resinas e tintas, perfumes, objetos, fármacos, cosméticos, alimentos e outros produtos foram expostos nessa sala. Painéis chamavam a atenção para a arborização urbana e seu papel na qualidade ambiental e no bem- estar psicológico nas cidades; para a necessidade de conservação e recuperação das matas ciliares e fragmentos florestais para a manutenção da quantidade e qualidade dos recursos hídricos; e, enfim, para a necessidade de um melhor aproveitamento dos recursos florestais durante sua transformação em produtos, permitindo a redução da geração de resíduos e da intensidade de exploração florestal.

Por fim, na última sala o visitante recebia informações sobre os desafios atuais para a conservação das florestas, sobre as ações para sua viabilização e sobre os trabalhos de ensino, pesquisa e extensão universitários desenvolvidos pelo Departamento de Ciências Florestais da ESALQ-USP, que têm contribuído para o enfrentamento desse desafio, sendo convidado a refletir sobre o seu papel e sua contribuição para a manutenção dos recursos florestais.

Os grupos de visita guiada tiveram, ainda, oportunidade de visitar um fragmento florestal localizado aos fundos do museu para uma experiência sensorial mostrando a diferença no microclima e para observação da diversidade de espécies numa pequena mata. Esse trabalho foi monitorado por quatro estagiários dos cursos de graduação em Engenharia Florestal e Gestão Ambiental da ESALQ-USP, capacitados para receber e trabalhar os temas propostos junto ao público de estudantes do ensino fundamental e médio, além da educação infantil.

$\mathrm{Na}$ elaboração do projeto expositivo, o grande desafio foi desenvolver um projeto que, com poucos recursos financeiros e num espaço limitado, conseguisse abordar os diferentes aspectos e visões relacionados à importância das florestas brasileiras em seus múltiplos aspectos e, além disso, permitisse a itinerância, possibilitando sua montagem nos demais campi da USP e outros locais que tiverem interesse. 


\section{RESULTADOS}

A exposição ocorreu no Museu e Centro de Ciências, Educação e Artes "Luiz de Queiroz" no período de 5 de setembro a 4 de outubro de 2011. Sendo que a partir de 2012 deverá passar pelos demais campi da USP e outros locais interessados em recebê-la.

O número total de visitantes no período foi de 1374 pessoas, com predominância de alunos do Ensino Fundamental das redes pública e privada (Tabela 1).

Tabela 1 Origem dos visitantes no período de exposição na ESALQ-USP

\begin{tabular}{lc}
\hline ORIGEM & NÚMERO TOTAL DE VISITANTES \\
\hline Escola Pública - Ensino Fundamental & 552 \\
\hline Escola Pública - Ensino Médio & 148 \\
\hline Escola Particular - Ensino Fundamental & 73 \\
\hline Escola Particular - Ensino Médio & 0 \\
\hline Escolas de Educação Infantil & 167 \\
\hline Projetos Sociais & 165 \\
\hline Programas de Atendimento à Portadores de & 98 \\
\hline Deficiência Física e Intelectual & 171 \\
\hline Demais visitantes & 1374 \\
\hline TOTAL
\end{tabular}

A adesão do Museu ao Programa Cultura é Currículo da Secretaria de Educação do Estado de São Paulo foi um fator relevante para a viabilização das visitas pelas escolas públicas de ensino fundamental.

Esse programa visa proporcionar melhor qualidade de ensino na escola pública estadual, democratizando o acesso de alunos e professores a equipamentos, bens e produções culturais que constituem patrimônio cultural da sociedade, buscando uma formação ampla de ensino-aprendizagem e maior inserção social. Propicia, ainda, um fortalecimento do ensino através de novas formas e possibilidades de desenvolvimento de conteúdos curriculares pela diversificação das situações de aprendizagem, reforçando o caráter investigativo. E, para tanto, fornece infraestrutura necessária ao transporte dos alunos através do Projeto Escola Sai da Escola.

O projeto expositivo forneceu material e incentivo para o trabalho do tema conservação das florestas em várias disciplinas. As imagens, produtos e os objetos artesanais dos povos das florestas subsidiam atividades de artes e reflexões sobre os processos de produção, os recursos florestais utilizados, o conhecimento tradicional envolvido, a forma de vida dessa população e seu papel na conservação das florestas brasileiras; os textos literários apresentam as diferentes visões sobre o assunto, apresentadas por escritores brasileiros, que podem ser inseridos nos conteúdos do programa de 
língua portuguesa e estudos sociais; os textos históricos, a percepção dos primeiros colonizadores, que pode ser tratada nas aulas de história, gerando discussões sobre as formas de relação sociedade-natureza ao longo do tempo; o material científico tratou de aspectos sobre flora, fauna, manejo florestal, recursos hídricos, entre outros, ricos para utilização nas aulas de biologia e educação ambiental.

Já o programa Profissões na ESALQ foi fundamental para a viabilização das visitas dos estudantes do Ensino Médio. Esse programa foi criado com o objetivo de intensificar a divulgação dos cursos de graduação e aproximar estudantes do ensino médio do universo acadêmico. Para tanto, a ESALQ oferece às escolas o transporte, lanche e visita guiada, com atividades teóricas e práticas. A visita à exposição permitiu a esses alunos um maior contato com o curso de graduação em Engenharia Florestal, com as atividades profissionais do Engenheiro Florestal e com as questões atuais sobre conservação dos biomas florestais brasileiros, foco principal da exposição (Figura 4).

O formato da exposição favoreceu, ainda, o desenvolvimento de atividades adequadas à visitação de seis grupos de crianças e adolescentes, deficientes físicos e intelectuais, atendidos pelo Centro de Reabilitação de Piracicaba. O uso de imagens, objetos, animais taxidermizados, jogos, sons e a visita ao fragmento florestal, criaram experiências lúdicas e educativas, baseadas em elementos concretos, que apesar de não terem sido especificamente pensadas para esse grupo, criou um ambiente propício ao enriquecimento da vivência educativa e de lazer desses visitantes.

Devido ao pequeno tempo de exposição no ano de 2011, por limitações na agenda do museu, o evento teve maior impacto local. Ainda assim, contou com visitantes de outros municípios, estados e países, principalmente profissionais e estudantes que estiveram na ESALQ no período.

As visitas individuais também foram em menor número, em grande parte devido às restrições de horário de funcionamento do museu, que não abre nos finais de semana quando o parque da ESALQ recebe o maior número de frequentadores.

A exposição teve também uma boa visibilidade, resultando em mais de 30 entrevistas em meio impresso e eletrônico, além de cinco em rádio e televisão.

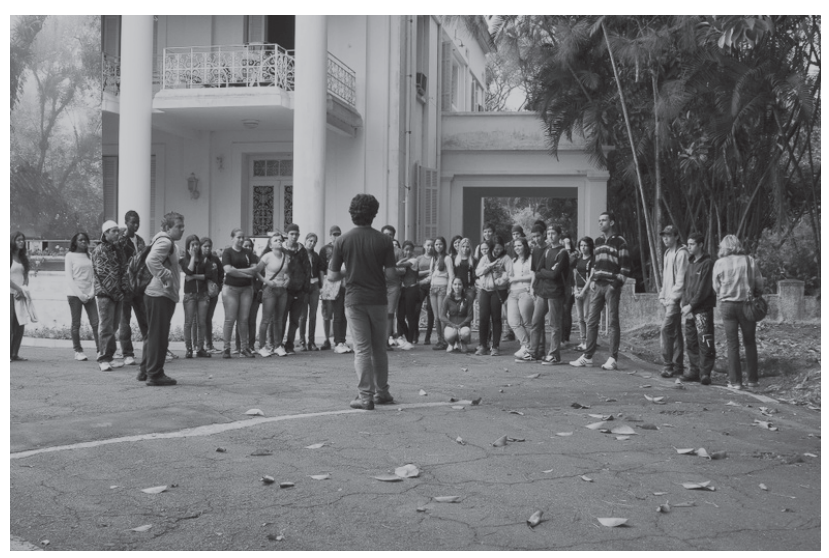

Figura 4 - Visita de alunos do ensino médio do programa Profissões na ESALQ 


\section{CONSIDERAÇÕES FINAIS}

A atualidade do tema e o formato da exposição despertaram o interesse das escolas, que foi o público predominante nessa exposição. A participação da ESALQ nos programas governamentais, além de iniciativas próprias de fomento à visitação da escola por alunos de Ensino Médio, foi fundamental para viabilizar a participação dos estudantes.

O projeto expositivo com uso de um rico e diversificado material contribuiu para a sensibilização dos visitantes e para fomentar a continuidade da discussão sobre o tema conservação dos recursos florestais na escola, com a possibilidade de inserção do conteúdo em diferentes disciplinas.

Mesmo que de maneira não intencional, os materiais e o formato adotado para a exposição propiciaram uma rica experiência para os visitantes portadores de deficiência física e intelectual.

\section{REFERÊNCIAS BIBLIOGRÁFICAS}

[1] ANCHIETA, Padre José de. Carta de São Vicente, 1560. São Paulo: Conselho Nacional da Reserva da Biosfera da Mata Atlântica, Caderno n. 7 - Série Documentos Históricos, 1997, 28 p.

[2] COMITÊ CHICO MENDES - MINISTÉRIO DO MEIO AMBIENTE. Caderno Povos da Floresta. Rio Branco, 2007.

[3] FAO - Food and Agriculture Organization of The United Nations. State of the world's forests 2011. Roma, 2011.

[4] LUCIANO, G. S. O Índio Brasileiro: o que você precisa saber sobre os povos indígenas no Brasil de hoje. Brasília: Ministério da Educação, Secretaria de Educação Continuada, Alfabetização e Diversidade; LACED/Museu Nacional, 2006.

[5] VIANA, V. M. Desatando o nó entre florestas e mudanças climáticas. Manaus: Fundação Amazonas Sustentável, 2009. Disponível em www.fas-amazonas.org. Acesso em: 23 jul. 2011.

[6] WWF International. Planeta Vivo - Relatório 2010 Biodiversidade, biocapacidade e desenvolvimento. Brasília, 2010.

\section{AGRADECIMENTOS}

Agradecemos à Pró-Reitoria de Cultura e Extensão da Universidade de São Paulo, que através do Fundo de Fomento às Iniciativas de Cultura e Extensão financiou a produção dos painéis utilizados nessa exposição; a diretoria da ESALQ-USP e a Prefeitura do Campus "Luiz de Queiroz", que disponibilizaram recursos humanos, materiais e financeiros para sua viabilização; a Fundação Amazonas Sustentável, por ceder o uso de imagens e vídeos de seus projetos na região Amazônica; a Reserva da Biosfera da Mata Atlântica, especialmente ao presidente do Conselho Nacional da Reserva da Biosfera da Mata Atlântica e coordenador da Rede Brasileira de Reservas 
da Biosfera, Clayton F. Lino, que disponibilizou o maravilhoso material fotográfico de sua autoria para produção dos painéis.

ADRIANA MARIA NOLASCO professora doutora do Departamento de Ciências Florestais da Escola Superior de Agricultura "Luiz de Queiroz" da Universidade de São Paulo. CP o9 - CEP 13418-9oo Piracicaba-SP - e-mail: amnolasc@esalq.usp.br.

CÉliA Regina Vello educadora do Museue Centro de Ciências, Educação e Artes "Luiz de Queiroz" - e-mail: celiavel@esalq.usp.br

EDNO APARECIDO DARIO especialista em Museografia e Exposições, Museu e Centro de Ciências, Educação e Artes "Luiz de Queiroz" - e-mail: eadario@esalq.usp.br. 